This item was submitted to Loughborough's Research Repository by the author.

Items in Figshare are protected by copyright, with all rights reserved, unless otherwise indicated.

\title{
The acquisition of preschool mathematical abilities: theoretical, methodological and educational considerations
}

PLEASE CITE THE PUBLISHED VERSION

http://dx.doi.org/10.1080/10986065.2015.1016810

\section{PUBLISHER}

(C) Taylor \& Francis (Routledge)

\section{VERSION}

AM (Accepted Manuscript)

\section{PUBLISHER STATEMENT}

This work is made available according to the conditions of the Creative Commons Attribution-NonCommercialNoDerivatives 4.0 International (CC BY-NC-ND 4.0) licence. Full details of this licence are available at: https://creativecommons.org/licenses/by-nc-nd/4.0/

\section{LICENCE}

CC BY-NC-ND 4.0

\section{REPOSITORY RECORD}

Torbeyns, Joke, Camilla K. Gilmore, and Lieven Verschaffel. 2019. "The Acquisition of Preschool Mathematical Abilities: Theoretical, Methodological and Educational Considerations”. figshare. https://hdl.handle.net/2134/17016. 
The acquisition of preschool mathematical abilities: Theoretical, methodological and educational considerations. An introduction

\author{
Joke Torbeyns $^{1}$, Camilla Gilmore ${ }^{2}$, and Lieven Verschaffel ${ }^{1}$ \\ ${ }^{1}$ KU Leuven, Belgium \\ ${ }^{2}$ Loughborough University, U.K.
}

\begin{abstract}
Author Note
This research was partially supported by Grant GOA 2012/10 "Number sense: analysis and improvement" from the Research Fund KU Leuven, Belgium (Joke Torbeyns, Lieven Verschaffel) and a Royal Society Dorothy Hodgkin Fellowship (Camilla Gilmore).

Correspondence concerning this article should be addressed to Joke Torbeyns, KU Leuven, Centre for Instructional Psychology and Technology, Dekenstraat 2, 3000 Leuven, Belgium. Tel: +32 163257 18, E-mail: joke.torbeyns@ppw.kuleuven.be
\end{abstract}

Keywords: quantitative reasoning, counting, magnitude understanding, spontaneous focus on numerosity, preschool mathematical, and linguistic skills, home numeracy environment 


\section{The acquisition of preschool mathematical abilities: Theoretical, methodological and}

\section{educational considerations. An introduction}

Mathematical skills are crucial to success in modern Western societies. We are continuously confronted with mathematical information and tasks in both our professional and private daily life. During the last few decades, researchers have tried to unravel the basic structures and processes that contribute to mathematical proficiency in children, adolescents, and adults, mainly focusing on the domain of number and arithmetic (e.g., De Smedt, Noël, Gilmore, \& Ansari, 2013; Duncan et al., 2007; Fuchs et al., 2009; Gersten \& Chard, 1999). These studies have increased our understanding of people's mathematical development, and, to some extent, also provided building blocks for effective teaching strategies. However, they have not yet succeeded in revealing the full complexity of mathematical acquisition processes, particularly during the preschool years.

This special issue aims to complement our insights into the development of mathematical proficiency by bringing together six recent empirical studies and two discussant papers on the acquisition of key number and arithmetic knowledge and skills in preschoolers, an important but up until now rarely investigated age group (see, e.g., the recent review by De Smedt et al., 2013). In all these contributions, the authors explore how the interplay between preschoolers' key number and arithmetic skills and other subject and environmental factors, especially preschoolers' linguistic skills (e.g., phonological awareness, print knowledge) and home numeracy environment, contribute to children's more general mathematical competencies.

In this introduction, we first provide a brief overview of the major findings about the acquisition of key mathematical abilities that will be focused on in the contributions to the special issue, i.e., young children's quantitative reasoning competencies, counting skills, magnitude understanding and their tendency to spontaneously focus on numerosity. Next, we summarize some major findings concerning the complex relation between young children's 
early mathematical competencies and their linguistic skills, followed by a discussion of the influence of the characteristics of the home environment. We end this introduction with an overview of the structure and the content of the special issue.

\section{Quantitative Reasoning}

Departing from Piaget's logical operations framework (e.g., Piaget, Inhelder, \& Szeminska, 1960; Piaget \& Szeminska, 1952), it has often been argued that young children's logical or quantitative reasoning skills, i.e., their competencies to reason about the logical or quantitative relations among numbers and operations, are of primary importance for their further mathematical development. For a long time, young children's logical or quantitative reasoning skills were considered as central precursors of children's later mathematical development. However, from the 1970s on, the pivotal role of these so-called Piagetian skills has been questioned. By contrast, an ever-growing number of researchers formulated theoretical and empirical arguments for the importance of young children's counting and magnitude understanding skills (Verschaffel, Greer, \& De Corte, 2007). Nowadays, we are evidencing renewed research attention for young children's logical reasoning skills and their importance for people's further mathematical development (e.g., Nunes, Bryant, Barros, \& Sylva, 2012). But, rather than being the primary or even only key mathematical skill, children's reasoning competencies are seen as complementary to other, more "pure" number and arithmetic skills, with independent and important contributions of both the former and the latter type of mathematical abilities to children's further mathematical development.

Recent studies on children's logical or quantitative reasoning competencies (e.g., Nunes et al., 2012) focus on three key logical relations between numbers and operations, namely (a) correspondence, (b) additive composition, and (c) inverse relations between operations.

The first quantitative reasoning skill, correspondence, refers to children's understanding of one-to-one and one-to-many relations between sets of objects. If two sets of objects 
contain exactly the same number of items, then the items in the first set are in one-to-one correspondence with the items in the second set; this one-to-one correspondence understanding underlies children's knowledge of the principle of cardinality (e.g., Gelman \& Gallistel, 1978). One-to-many correspondences are important for children's understanding of multiplication and division operations: If the first set of objects is in one-to-three correspondence with the second set of objects, and if the first set of objects is also in one-tothree correspondence with the third set of objects, then the second and the third set of objects are equal. Although children's understanding of one-to-one correspondences attracted the attention of many researchers, children's knowledge of one-to-many correspondences has been far less studied, limiting our insights into this quantitative reasoning skill (but see Frydman \& Bryant, 1988; Nunes \& Bryant, 1996; Nunes et al., 2007, 2012; Piaget, 1952).

The second quantitative reasoning skill, additive composition, applies to relations between quantities as well as operations. Additive composition indicates that any quantity or addition operation is composed of, or can be divided into, two other quantities or addition operations respectively; any quantity or addition operation can thus be expressed as the sum of two other quantities or operations respectively (e.g., $6=4+2$; adding 6 is the same as first adding 4 and next adding 2). Understanding additive composition is an important precursor for children's understanding of the structure of numbers and the structure of the number system; it also underlies children's fluency in performing addition operations. The scarce number of studies on additive composition indicates that this quantitative reasoning skill is not easily acquired, with evidence for first understanding of the additive composition of quantities around the age of 6 (Nunes \& Bryant, 1996) and of the additive composition of operations around the age of 11 (Brown, 1981; Vergnaud, 1982).

The third quantitative reasoning skill, inverse relations between operations, refers to the fact that adding and subtracting the same quantity, or multiplying and dividing by the same 
quantity, cancel each other out (e.g., $6+3-3=6 ; 6 \times 3 / 3=6$ ). Understanding the inverse relation between addition and subtraction and between multiplication and division is important for the acquisition of clever computation strategies such as the indirect addition strategy (i.e., answering $12-9$ by counting on from 9 until 12; cf. Torbeyns, De Smedt, Stassens, Ghesquière, \& Verschaffel, 2009; Verschaffel, Baroody, \& Torbeyns, 2009). The meta-analysis of Gilmore and Papadatou-Pastou (2009) on children's understanding of the inverse relation between addition and subtraction revealed large interindividual differences in both the age of acquisition of this understanding and its relation with children's arithmetic computational skills.

Although children's acquisition of quantitative reasoning skills recently re-attracted the interest of several researchers, this key mathematical competency is far less studied than children's development of counting and magnitude understanding skills (Verschaffel et al., 2009). Future studies are needed to unravel the developmental path of children's quantitative reasoning abilities in younger age groups, and more specifically before the start of formal mathematics instruction, with special attention to its interplay with other key mathematical precursors including counting and magnitude understanding skills. As a contribution to these promising venues for further research, this special issue includes recent empirical data on the refinement and validation of tasks designed to assess quantitative reasoning skills in these younger age groups (see Nunes, Bryant, Evans, \& Barros, this issue).

\section{Counting}

As outlined above, the theoretical conceptualisation and education practice relating to the development of numerical understanding were heavily influenced by Piaget's logical operations framework (e.g., Piaget et al., 1960; Piaget \& Szeminska, 1952), in which counting was seen as merely a rote skill, unimportant for children's further mathematical development until the major logical foundations are acquired. However, during the last 
decades, an increasing number of researchers has questioned the pivotal role of these logical operations in children's mathematical development and has shown, at the same time, the importance of children's verbal and object counting knowledge and skills for this development (Verschaffel et al., 2007).

Verbal counting refers to children's ability to verbally produce the number word sequence in forward and backward order. The (older) developmental studies of Fuson and colleagues (Fuson \& Hall, 1983; Fuson, Richards, \& Briars, 1982) provided empirical evidence for two overlapping phases of verbal counting development. In the first phase, the acquisition phase, children learn the conventional sequence of the verbal number words. During this phase, children understand the number word sequence as a single, connected serial whole from which the different number words cannot be produced separately. In the second phase, the elaboration phase, children gradually learn to decompose the number word sequence into its separate number words and construct relations among these number words. This progression enables children to produce the verbal number word sequence in both directions and starting from any number (e.g., starting to count on from the number 5). In line with the latter, international and cross-cultural studies revealed that the acquisition of verbal counting skills cannot be reduced to merely "rote counting", as verbal counting requires a basic understanding of the principles and patterns that govern the cultural- and languagespecific number system (see Fuson [1992] and Clements \& Sarama [2007] for reviews on this topic).

The development of children's object counting competencies, that is, their ability to count a set of objects and determine its cardinality, does not only involve a good mastery of the verbal number word sequence - or verbal counting skills - but also (a) a thorough understanding of the counting principles and (b) the coordination of the production of counting words with indicator actions as pointing to or moving objects (Clements \& Sarama, 
2007). According to Gelman and Gallistel (1978), five counting principles govern people’s object counting, namely (a) the one-one principle, defined as assigning one and only one number word to each object that needs to be counted; (b) the stable order principle, defined as always producing the number words in the same order; (c) the cardinal principle, defined as understanding that the last stated number word indicates the number of objects in the set; (d) the order irrelevance principle, referring to the fact that the order in which objects are counted is irrelevant; and (e) the abstraction principle, stating that the first four principles can apply to any set of objects. A task that is particularly well-suited to investigate children's understanding of these counting principles, is the Puppet Counting (or Error Detection) task (e.g., Cirino, 2011; Geary, 2011; Geary, Brown, \& Samaranayake, 1991). In this task, children are instructed to evaluate whether a puppet has counted correctly, respecting the basic principles for valid object counting, or not. Using this task, an increasing number of researchers provided empirical evidence for preschoolers' understanding of the counting principles as well as support for mathematically weaker children's difficulties in grasping these principles (Clements \& Sarama, 2007; Geary, 2011).

In addition to acquiring a thorough understanding of the five counting principles, the development of object counting skills requires motoric progression. To correctly count a set of objects, children must also be able to accurately coordinate their verbal number word utterances with their pointing or moving actions during the counting process. Immature coordination competencies result in asynchronous object counting acts. The coordination of the verbal production of the number word sequence and the behavioural moves that accompany the counting act allows correct object counting, by simultaneously or synchronously stating the verbal number word and pointing to or moving the object that is counted (= simultaneous or synchronous counting). A milestone in children's object counting development is the mastery of resultative counting skill, defined as the ability to connect the 
verbal number words stated during the counting process to the number of objects in the set counted; or, in other words, children's ability to correctly answer the question "How many?" by only mentioning the verbal number word they stated as the last number word in the counting act. Resultative counting involves (explicitly or implicitly) understanding the cardinal principle, and is mastered by most children at preschool age already (Clements \& Sarama, 2007).

Although it can be theoretically argued that young children's counting skills are pivotal for their further mathematical development, due to their role in acquiring a thorough understanding of the number sequence and in developing adequate computation strategies (Geary, 2004), empirical evidence on the predictive role of counting for the acquisition of more advanced mathematical competencies remains rather scarce (but see Aunola, Leskinen, Lerkkanen, \& Nurmi, 2004; Geary, Hoard, \& Hamson, 1999; Koponen, Aunola, Ahonen, \& Nurmi, 2007; Koponen, Salmi, Eklund, \& Aro, 2012; Martin, Cirino, Sharp, \& Barnes, 2014). Moreover, the specific relation between preschoolers' counting skills and understanding and other key mathematical abilities such as magnitude understanding has been rarely studied (but see Ebersbach \& Erz, 2014; Ebersbach, Luwel, Frick, Onghena, \& Verschaffel, 2008; and Simms, Muldoon, \& Towse, 2013, for studies in older age groups). The fine-grained analysis of the role of preschoolers' counting understanding and counting skills in the acquisition of other key mathematical abilities and of more advanced mathematical competencies thus offers interesting avenues for further research, which are addressed in the contributions to this special issue (see Ebersbach, Luwel, \& Verschaffel, this issue; Hannula-Sormunen, Lehtinen, \& Räsänen, this issue).

In addition to these theoretical challenges, the tasks that are currently used to address preschoolers' counting competencies require careful consideration. As illustrated by various empirical studies on young children's counting skills, researchers currently apply a rich 
diversity of tasks that are all assumed to tap into children's counting competencies. To analyse young children's verbal counting skills, both simple counting tasks in which children are required to count as far as they can or until they are told to stop, starting from 1 (e.g., Cirino, 2011; Hannula, Räsänen, \& Lehtinen, 2007; Simms et al., 2013) and more advanced counting tasks in which children are instructed to count from a given number to another number (e.g., Ebersbach et al., 2008; Lipton \& Spelke, 2005) are applied. The same holds for the analysis of young children's object counting skills, relying on the above-mentioned "How many?" task in which children (simply) have to count a range of objects to determine the total number of objects in this range (e.g., Cirino, 2011; Hannula et al., 2007; Le Corre \& Carey, 2007) as well as on more complex "Give me N" tasks in which they have to produce the correct set of objects themselves (Wagner \& Johnson, 2011; Wynn, 1992). Up until now, the theoretical underpinnings of the different types of tasks as well as their methodological strengths and weaknesses have received scarce research attention. This special issue includes fine-grained comparative analyses of the theoretical and methodological characteristics of the different types of tasks (see Batchelor, Keeble, \& Gilmore, this issue).

\section{Magnitude Understanding}

During the last decade, several cognitive psychologists (e.g., Feigenson, Dehaene, \& Spelke, 2004; Piazza et al., 2010) have argued that humans are born with an evolutionary ancient system allowing them to represent and process numerical quantities or magnitudes, that is, the so-called Approximate Number System (ANS). In the ANS, numerical magnitudes are assumed to be represented approximately on a mental number line, with increasingly imprecise representations for increasing magnitudes (Dehaene, 2001). Magnitudes are represented nonsymbolically, but, over development, symbolic representations (e.g., verbal number words, Arabic numerals) are mapped onto these pre-existing nonsymbolic representations. Children's magnitude understanding is typically investigated with two types 
of tasks that are assumed to access their ANS numerosity representations, namely (a) nonsymbolic or symbolic magnitude comparison and approximate addition tasks, and (b) number line estimation tasks.

The first type of tasks, magnitude comparison and approximate addition tasks, involve the comparison of two sets of nonsymbolic or symbolic numerosities to indicate the largest set (e.g., Barth, Beckmann, \& Spelke, 2008; Gilmore, McCarthy, \& Spelke, 2007, 2010; Halberda \& Feigenson, 2008; Xenidou-Dervou, De Smedt, van der Schoot, \& van Lieshout, 2013). In magnitude comparison tasks, children are required to compare the magnitude of two given sets of numerosities, whereas in approximate addition tasks, they need to compare the result of adding two numerosities (first set) with another given numerosity (second set). Typically, children perform well on magnitude comparison and approximate addition tasks if the distance between the to be compared numerosities is large, but have more difficulties in correctly comparing numerosities at small distances (= distance effect), with performances increasing with age. Children's performances on these tasks are also characterised by a size effect, indicating that larger magnitudes have to be more distant from each other than smaller magnitudes in order to be discriminated accordingly. This size effect also decreases from infancy to adulthood, suggesting a higher sensitivity towards larger numerosities with increasing age. The above findings are all interpreted as an increasing precision of the representation of magnitude - or, stated otherwise, increasing magnitude understanding - with age (Gallistel \& Gelman, 2000, 2005; Piazza et al., 2010).

Next to magnitude comparison and approximate addition tasks, number line estimation tasks are also used to investigate children's magnitude understanding. Number line estimation tasks require children to estimate the position of a nonsymbolic or symbolic numerosity on an external number line (e.g., Booth \& Siegler, 2006; Siegler \& Opfer, 2003). Developmental data have shown that numerosities from larger ranges obey a logarithmic representation, 
while smaller numerosities are mentally represented as linearly increasing magnitudes. With increasing age, the mental representation becomes linear for larger numbers too. This logarithmic-to-linear representation shift is typically interpreted in terms of increasing precision of children's magnitude representations. However, the logarithmic-to-linear representation shift model has recently been challenged and has led to alternative accounts of these representations of number (Barth \& Paladino, 2011; Ebersbach et al., 2008; Moeller, Pixner, Kaufmann, \& Nuerk, 2009; see also Eriksson \& Häggström, 2014).

During the last decade, empirical studies on magnitude understanding provided converging evidence for the importance of this mathematical skill for children's further mathematical development. Correlational and longitudinal studies in typically developing children (e.g., Booth \& Siegler, 2006; De Smedt, Verschaffel, \& Ghesquière, 2009; Halberda \& Feigenson, 2008; Holloway \& Ansari, 2009) and studies in children with mathematical difficulties (e.g., Butterworth, 2005; De Smedt, Reynvoet, Swillen, Verschaffel, Boets, \& Ghesquière, 2009; Geary, Hoard, Nugent, \& Byrd-Craven, 2008; Landerl, Bevan, \& Butterworth, 2004; Rousselle \& Noël, 2007) demonstrated that children's magnitude understanding is related to, and even predictive of, their general mathematics achievement.

In the last few decades numerous empirical investigations of children's magnitude understanding, as measured with one or more of the above-mentioned tasks, have significantly increased our insights into the development of this key mathematical skill as well as its importance for people's further mathematical development. However, we are still confronted with important theoretical, methodological and educational questions that require further research.

A first set of unanswered questions relates to our theoretical understanding of children's magnitude representations. As outlined above, numerical magnitudes can be represented nonsymbolically and/or symbolically. It is generally assumed that newborns are already able 
to represent and manipulate nonsymbolic magnitudes (e.g., Xu \& Spelke, 2000). Over the course of development, children also develop the ability to represent and manipulate magnitudes in a symbolic way by using verbal number words and written Arabic numerals. Successful mathematical development requires children to map these symbolic representations onto the pre-existing nonsymbolic representations of magnitude (Lipton \& Spelke, 2005), a process by which formal numerical symbols acquire their meaning (Griffin, 2002). However, the nature and role of this mapping process are currently under discussion. Whereas some authors argue for a consistent and close mapping between symbolic and nonsymbolic representations in people's mathematical development (e.g., Gilmore et al., 2007, 2010; Mundy \& Gilmore, 2009; Xenidou-Dervou et al., 2013), others question the pivotal role of this mapping process (e.g., Kadosh, \& Walsh, 2009; Le Corre \& Carey, 2007; Lyons, Ansari, \& Beilock, 2012). This special issue aims at contributing to our understanding of the nature and role of symbolic onto nonsymbolic mappings in preschoolers' mathematical development by discussing the design and validation of a new mapping task in relation to preschoolers' acquisition of object counting skills (see Batchelor et al., this issue).

A second set of issues that require further research attention relates to the methods used to assess young children's magnitude understanding. Although magnitude comparison, approximate addition and number line estimation tasks are all assumed to directly access children's magnitude representations on their mental number line, the strengths and the weaknesses of these different types of tasks are currently under discussion. As argued in more detail by other authors (cf. Ebersbach, Luwel, \& Verschaffel, 2013; Gilmore et al., 2013; Sasanguie, Defever, Van den Bussche, \& Reynvoet, 2011), these tasks' theoretical underpinnings as well as their methodological constraints can be critically questioned and require careful consideration in future investigations using these tasks. As explained earlier, to assess young children's magnitude understanding, researchers mainly rely on magnitude 
comparison and number line estimation tasks. However, it is being increasingly argued that the performance on these tasks might not reflect the characteristics of the number representations per se (i.e., the number line account; Dehaene, 1997), but can rather be accounted for by the use of strategies which may (e.g., counting; Petitto, 1990 (e.g., the proportion judgment account; Barth \& Paladino, 2011) be related to numerical understanding (see, e.g., Sasanguie, 2013).

Finally, as children's magnitude understanding has been shown to be correlated to - and even predictive of - children's mathematical achievement, researchers recently tried to stimulate children's mathematical development on the basis of intervention programs, aiming at enhancing magnitude understanding in children before or at the beginning of systematic instruction in number and arithmetic at elementary school (e.g., Brankaer \& Meeus, 2009; Obersteiner, Reiss, \& Ufer, 2013; Ramani \& Siegler, 2008, 2011; Räsänen, Salminen, Wilson, Aunio, \& Dehaene, 2009; Siegler \& Ramani, 2008, 2009; Whyte \& Bull, 2008; Wilson, Dehaene, Dubois, \& Fayol, 2009). However, the number of intervention studies is currently still limited and the results are heterogeneous, ranging from very small effects after intensive training to large effects after short-term interventions. Moreover, most of these intervention studies are subject to serious methodological flaws, including the absence of a proper control group. The educational implications of the above results on the acquisition of magnitude understanding and on its pivotal role in children's concurrent and further mathematical development thus also provides an interesting avenue for future studies on this topic.

\section{Spontaneous Focus on Numerosity}

Recently, young children's attentional processes, and especially their tendency to spontaneously focus on the numerical characteristics of their environment (abbreviated to SFON), became an important research topic in the domain of elementary mathematics. As 
originally defined in Hannula (2005), SFON refers to children's spontaneous, self-initiated focus of attention on the exact number of a collection of items or incidents. SFON is defined as a specific attentional process, separate from more general attentional or motivational competences such as focusing and maintaining attention on the task situation. This spontaneous focus on exact number is assumed to promote children's self-initiated mathematical practice during daily-life activities and play, and consequently enhance their further mathematical development (Hannula, Lepola, \& Lehtinen, 2010). Although the relation between children's SFON, their self-initiated mathematical practice in daily-life and their further mathematical development was not yet empirically addressed, previous studies on children's SFON tendency before school age not only revealed large interindividual differences in children's spontaneous focus on number but also positive relations between preschool children's SFON and their acquisition of precursor and later mathematical competencies (Hannula, 2005; Hannula \& Lehtinen, 2001, 2005; Hannula et al., 2007; Potter, 2009).

Children's SFON tendency is typically investigated using Imitation tasks, as the Parrot or Mailbox Imitation tasks (for a detailed description of SFON tasks, see Hannula, 2005, and Hannula-Sormunen, in press). In these tasks, children are confronted with an adult feeding a parrot with a small number of differently-coloured berries or posting a small number of differently-coloured envelopes into a mailbox, and instructed to "do exactly the same" as the adult did. Children tend to differ widely in their spontaneous focus on the number of berries or envelopes during task execution. These interindividual differences in children's SFON tendency are shown to be positively related to their development of counting and number sequence skills before school age (Hannula, 2005; Hannula \& Lehtinen, 2001; 2005; Hannula et al., 2007; Potter, 2009). Moreover, recent longitudinal studies by Hannula and colleagues revealed that young children's SFON tendency at preschool age is an important predictor of 
their mathematical development during the first years of formal schooling and even at the end of the primary school (Hannula et al., 2010; Hannula-Sormunen, in press). Given the importance of SFON for children's further mathematical development, a first intervention study on the stimulation of young children's SFON in day care settings was set up by this same group of researchers. Although still tentative and requiring further investigation in other, larger and also older age groups, the results of this first study were positive, demonstrating that 3-year-olds' SFON tendency can be enhanced through guided focusing activities in preschool (Hannula, Mattinen, \& Lehtinen, 2005).

Notwithstanding the positive findings on the pivotal role of young children's SFON tendency in the acquisition of later mathematical skills, the complex interplay between preschoolers' SFON and other key mathematical abilities at preschool age requires further research attention. Moreover, as young children's SFON tendency is currently studied with different types of Imitation tasks as well as other types of tasks that are assumed to tap onto the same underlying processes (e.g., Model task, Finding task; see Batchelor, 2015; HannulaSormunen, in press), the reliability and validity of the diverse SFON tasks needs to be carefully investigated to allow valid conclusions about the developmental path of this mathematical precursor and in relation to other important mathematical competencies (for a critical study of different types of SFON tasks, see Batchelor, 2015). The contribution of Hannula-Sormunen et al. (this issue) addresses several of these important pending issues.

\section{Early Mathematical Abilities in Relation to Young Children's Linguistic Skills}

Although generally defined as two clearly distinct and different academic domains, children's performances in the domain of mathematics and in the domain of reading are positively, and even predictively, related to each other (e.g., Duncan et al., 2007; Hecht, Torgesen, Wagner, \& Rashotte, 2001; Juel, 1988; LeFevre, Fast, et al., 2010). Children's mathematical and reading skills are related from very early ages on, before the start of formal 
school instruction in these domains (McClelland et al., 2007; Welsh, Nix, Blair, Bierman, \& Nelson, 2010). Departing from Dehaene and colleagues' triple-code model for numerical cognition (cf. Dehaene, Molko, Cohen, \& Wilson, 2004; Dehaene, Piazza, Pinel, \& Cohen, 2003), LeFevre and colleagues (2010) proposed and validated a model of mathematical development involving three different precursor pathways, namely a linguistic, spatial and quantitative pathway. By following children's acquisition of early and later mathematical skills longitudinally from preschool until the first years of formal mathematics instruction, LeFevre and colleagues (2010) provided empirical evidence for the unique and independent contributions of the linguistic and the quantitative precursor pathways to children's mathematical development.

These researchers' definition of the linguistic pathway involved two of the three primary early literacy skills that are generally assumed important for both mathematics and reading development, namely phonological processing and oral language skills. In addition to phonological processing and oral language skills, children's print knowledge is distinguished as an important (linguistic) precursor for their further mathematical development (Purpura, Hume, Sims, \& Lonigan, 2011).

The first early literacy skill, phonological processing abilities or phonological awareness, refers to children's abilities to analyse the sound structure of oral language and (consequently) manipulate language through tasks involving rhyme detection, matching, blending and/or deleting parts of words (Wagner \& Torgesen, 1987). The second early literacy skill, oral language, includes children's word knowledge, vocabulary and understanding of grammatical rules (Storch \& Whitehurst, 2002). The third early literacy skill, print knowledge, includes a child's knowledge of letter names and sounds, words, and basic conventions about books and print. Each of these three early literacy skills can arguably be related to the acquisition of children's symbolic magnitude understanding, knowledge of 
verbal number words and written Arabic numerals, understanding of mathematical concepts and/or acquisition of fact knowledge.

Numerous researchers empirically investigated the assumed positive and predictive relations between children's phonological awareness skills and their specific as well as general mathematical competencies (e.g., De Smedt, Taylor, Archibald, \& Ansari, 2010; Fuchs et al., 2006, 2009; Krajewski \& Schneider, 2009; Martin et al. 2014; Savage, Carless, $\&$ Ferraro, 2007). Taken together, these studies provided empirical evidence for the pivotal role of young children's phonological awareness skills in the acquisition and further development of mathematical competencies. Although far less studied than young children's phonological awareness skills, oral language also proves positively and predictively related to children's mathematical development (Hooper, Roberts, Sideris, Burchinal, \& Zeisel, 2010; Romano, Babchishin, Pagani, \& Kohen, 2010; Toll \& Van Luit, 2014). A limited number of investigations on young children's print knowledge and mathematics, indicated that the former (linguistic) skill is correlates with and even predicts the latter (mathematical) competencies (Matthews, Ponitz, \& Morrison, 2009; Piasta, Purpura, \& Wagner, 2010; Purpura et al., 2011). However, additional empirical evidence on these relations is needed to validate the available results, an issue addressed in the contribution of Purpura and Napoli (this issue).

\section{Early Mathematical Abilities and the Characteristics of the Home Environment}

Already at school entry, children differ widely in their basic reading and mathematical competencies. These interindividual differences in children's basic academic skills suggest that the home environment plays a crucial role in the fluent acquisition of early literacy and mathematical competencies (cf. Ramani \& Siegler, 2011). Although the contribution of the home literacy environment to children's literacy development has been studied in great detail, resulting in theoretical models on the complex interplay between these two variables (cf. 
Sénéchal \& LeFevre, 2002), the relation between the characteristics of the home numeracy environment and children's mathematical development have been explored in far less detail (but see Blevins- Knabe \& Musun-Miller, 1996; Kleemans, Peeters, Segers, \& Verhoeven, 2012; LeFevre et al., 2009; LeFevre, Polyzoi, Skwarchuk, Fast, \& Sowinski, 2010).

Recently, Skwarchuk, Sowinski, and LeFevre (2014) proposed a theoretical model on the relation between young children's home numeracy environment and their early mathematical development, departing from the scarce number of empirical studies on this relation and their home literacy model. In their home numeracy model, Skwarchuk et al. (2014) distinguish between two types of home numeracy experiences, namely (a) formal numeracy experiences, referring to parents' explicit teaching activities in the domain of mathematics, and (b) informal numeracy experiences, involving daily-life and playful situations that allow parents to interact mathematically with the child (e.g., playing number board games, cooking activities). Using questionnaires, parents' formal and informal numeracy activities were analysed; in addition to these activities, parents' general academic expectations were questioned as well.

Confirming the results of previous studies, Skwarchuk and colleagues (2014) found empirical support for the expected positive relation between young children's home numeracy experiences and their early mathematical development. As expected, the parents' academic expectations contributed only indirectly, via the home numeracy activities, to this development. Interestingly, and complementing previous work on this topic, the results of Skwarchuk and colleagues (2014) revealed distinct and unique pathways between the type of home numeracy experiences and children's early mathematical skills: Whereas young children's formal home numeracy experiences uniquely contributed to their acquisition of symbolic number knowledge, informal home numeracy experiences uniquely contributed to the development of their nonsymbolic arithmetic skills. Although promising, these 
conclusions on the complex interplay between young children's home numeracy experiences and their further mathematical development, in general as well as on specific subskills, require further research attention to both deepen and broaden our insights into this complex domain. The study of Segers, Kleemans, and Verhoeven (this issue) focuses on the relation between preschoolers home numeracy and home literacy environment and their acquisition of key mathematical competencies.

\section{Overview of the Special Issue}

Despite the ever-growing research attention on children's mathematical development in the last few decades, our insights into the developmental paths at very young, that is, preschool, ages are still limited. Moreover, the complex interplay between, on the one hand, preschoolers' key mathematical competencies and, on the other hand, their concurrent and further mathematical development and linguistic skills and context factors including home numeracy experiences offer interesting and important venues for future investigations. This special issue aims to deepen and refine our understanding of preschoolers' mathematical development by addressing the above mentioned weaknesses and perspectives for further study.

In the first contribution, Batchelor, Keeble, and Gilmore focus on the nature and the timing of the process of mapping symbolic and nonsymbolic magnitude representations in preschool children in relation to their counting competencies, that is, understanding of cardinality. Using a newly-developed mapping task suited for preschool children, they not only deepen our theoretical understanding of this fundamental process, but also add to the methodological state-of-the-art in this domain.

In the second contribution, Ebersbach, Luwel, and Verschaffel analyse the complex interplay between two key mathematical abilities in preschool and elementary school children, that is, the interplay between children's magnitude understanding as measured by a 
number line estimation task that either does or does not involve additional reference points, and their familiarity with the numbers in the corresponding number domain. Doing this, these authors provide building blocks for furthering our theoretical and methodological insights into children's acquisition of magnitude understanding as investigated with number line estimation tasks.

The third contribution, of Hannula-Sormunen, Lehtinen, and Räsänen, presents a longitudinal study on preschoolers' acquisition of three key mathematical abilities, that is, subitizing based enumeration, counting, and SFON, in relation to their mathematical competencies at the end of primary school. Starting from a model delineating the direct and indirect relations between these three key mathematical abilities and children's further mathematical development, the authors complement our theoretical understanding of the developmental pathways from preschool age up to the end of primary school. The longitudinal design of the presented study and the variety of tasks used to address preschoolers mathematical abilities offer interesting avenues for future studies in this domain.

Nunes, Bryant, Evans, and Barros complement the previous contributions by focusing on young children's quantitative reasoning skills (fourth contribution). In their contribution, Nunes and colleagues present a newly-developed task to assess 5-year-olds' quantitative reasoning skills and discuss the psychometric qualities of this task as evidenced in their longitudinal study. As such, this contribution significantly adds to the further study and improvement of young children's quantitative reasoning development.

In the fifth contribution, Purpura and Napoli address the largely unexplored interplay between preschoolers' language and print knowledge skills and their early mathematical competencies. By involving a large number of preschool children aged 3 to 5 years, the authors explore the relations between these early literacy skills at different stages in the mathematical development process. Their results provide new and important insights into the 
complex interplay between these less frequently investigated linguistic competencies and mathematical precursors in young age groups.

The sixth contribution, by Segers, Kleemans, and Verhoeven, aims at unravelling the unique contributions of the home literacy and the home numeracy environment to preschoolers' mathematical development. Using questionnaires addressing parent expectations and activities in both the domain of literacy and the domain of numeracy and controlling for children's general cognitive competencies, these authors complement our understanding of the unique role of preschoolers' home numeracy expectations for their mathematical development.

The special issue ends with two discussant contributions by two experts in the domain of (preschool) mathematical development. In their papers, David Geary and Douglas Clements discuss the major issues and findings in the different contributions from, respectively, a cognitive psychological and mathematics educational point of view. As such, they integrate the different contributions to the special issue into one comprehensive whole. 


\section{References}

Aunola, K., Leskinen, E., Lerkkanen, M.-L., \& Nurmi, J.-E. (2004). Developmental dynamics of math performance from pre-school to Grade 2. Journal of Educational Psychology, 96, 699-713. doi:10.1037/0022-0663.96.4.699

Barth, H., Beckmann, L., Spelke, E. S. (2008). Nonsymbolic, approximate arithmetic in children: Abstract addition prior to instruction. Developmental Psychology, 44, 14661477. doi: $10.1037 / \mathrm{a} 0013046$

Barth, H. C., \& Paladino, A. M. (2011). The development of numerical estimation: Evidence against a representational shift. Developmental Science, 14, 125-135. Doi:

10.1111/j.1467-7687.2010.00962.x

Batchelor, S. (2015). Dispositional factors affecting children's early numerical development (Doctoral dissertation). Retrieved from Loughborough University Institutional Repository.

Blevins-Knabe, B., \& Musun-Miller, L. (1996). Number use at home by children and their parents and its relationship to early mathematical performance. Early Development and Parenting, 5(1), 35-45.

Booth, J. L., \& Siegler, R. S. (2006). Developmental and individual differences in pure numerical estimation. Developmental Psychology, 41, 189-201. doi: 10.1037/00121649.41.6.189

Brankaer, C., \& Meeus, H. (2009). De getallenrace: onderzoek naar het effect van een remediëringsprogramma bij zwakke rekenaars uit het eerste leerjaar [The Number Race game: A study on the effectiveness of this intervention in first graders with mathematical difficulties] (Unpublished master's thesis). University of Leuven, Faculty of Psychology and Educational Sciences, Leuven, Belgium. 
Brown, M. (1981). Number operations. In K. Hart (Ed.), Children's understanding of mathematics: 11-16 (pp. 23-47). Windsor, UK: NFER-Nelson.

Butterworth, B. (2005). Developmental dyscalculia. In J. I. D. Campbell (Ed.), Handbook of mathematical cognition (pp. 455-467). Hove, UK: Psychology Press.

Cirino, P. T. (2011). The interrelationships of mathematical precursors in kindergarten. Journal of Experimental Child Psychology, 108, 713-733. doi: 10.1016/j.jecp.2010.11.004

Clements, D. H., \& Sarama, J. (2007). Early childhood mathematics learning. In F. K. Lester Jr. (Ed.), Second handbook of research on mathematics teaching and learning (pp. 461555). Charlotte, NC: Information Age.

De Smedt, B., Noël, M. P., Gilmore, C., \& Ansari, D. (2013). How do symbolic and nonsymbolic numerical magnitude processing skills relate to individual differences in children's mathematical skills? A review of evidence from brain and behavior. Trends in Neuroscience and Education, 2(2), 48-55. doi: 10.1016/j.tine.2013.06.001

De Smedt, B., Reynvoet, B., Swillen, A., Verschaffel, L., Boets, B., \& Ghesquière, P. (2009). Basic number processing and difficulties in single-digit arithmetic: Evidence from VeloCardio-Facial Syndrome. Cortex, 45, 177-188. doi: 10.1016/j.cortex.2007.06.003

De Smedt, B., Taylor, J., Archibald, L., \& Ansari, D. (2010). How is phonological processing related to individual differences in children's arithmetic? Developmental Science, 13, 508-520. doi: 10.1111/j.1467-7687.2009.00897.x

De Smedt, B., Verschaffel, L., \& Ghesquière, P. (2009). The predictive value of numerical magnitude comparison for individual differences in mathematics achievement. Journal of Experimental Child Psychology, 103, 469-479. doi:10.1016/j.jecp.2009.01.010

Dehaene, S. (1997). The number sense: How the mind creates mathematics. London, UK: Penguin Press. 
Dehaene, S. (2001). Précis of the number sense. Mind \& Language, 16(1), 16-36.

Dehaene, S., Molko, N., Cohen, L., \& Wilson, A. J. (2004). Arithmetic and the brain. Current Opinion in Neurobiology, 14, 218-224. doi: 10.1016/j.conb.2004.03.008

Dehaene, S., Piazza, M., Pinel, P., \& Cohen, L. (2003). Three parietal circuits for number processing. Cognitive Neuropsychology, 20, 487-506. doi: 10.1080/02643290244000239

Duncan, G. J., Claessens, A., Huston, A. C., Pagani, L. S., Engel, M., Sexton, H., ... Japel, C. (2007). School readiness and later achievement. Developmental Psychology, 43, 14281446. doi:10.1037/0012-1649.43.6.1428

Ebersbach, M., \& Erz, P. (2014). Symbolic versus non-symbolic magnitude estimations among children and adults. Journal of Experimental Child Development, 128, 52-68. doi: 10.1016/j.jecp.2014.06.005

Ebersbach, M., Luwel, K., Frick, A., Onghena, P., \& Verschaffel, L. (2008). The relationship between the shape of the mental number line and familiarity with numbers in 5-to 9-year old children: Evidence for a segmented linear model. Journal of Experimental Child Psychology, 99(1), 1-17. doi:10.1016/j.jecp.2007.08.006

Ebersbach, M., Luwel, K., \& Verschaffel, L. (2013). Comparing apples and pears in studies on magnitude estimations. Frontiers in Cognitive Science, 4, 332. doi: 10.3389/fpsyg.2013.00332

Eriksson, K., \& Häggström, O. (2014). Lord's paradox in a continuous setting and a regression artifact in numerical cognition research. PLoS One, 9, e95949. doi: 10.1371/journal.pone.0095949

Feigenson, L., Dehaene, S., \& Spelke, E. (2004). Core systems of number. Trends in Cognitive Sciences, 8, 307-314. 
Frydman, O., \& Bryant, P. E. (1988). Sharing and the understanding of number equivalence by young children. Cognitive Development, 3, 323-339. doi: 10.1016/08852014(88)90019-6

Fuchs, L. S., Fuchs, D., Compton, D. L., Powell, S. R., Seethaler, P. M., Capizzi, A. M., \& Fletcher, J. M. (2006). The cognitive correlates of third-grade skill in arithmetic, algorithmic computation, and arithmetic word problems. Journal of Educational Psychology, 98, 29-43. doi: 10.1037/0022-0663.98.1.29

Fuchs, L. S., Powell, S. R., Seethaler, P. M., Fuchs, D., Hamlett, C. L., Zumeta, R. O., Cirino, P. T., \& Fletcher, J. M. (2009). Remediating number combination and word problem deficits among students with mathematical difficulties: A randomized control trial. Journal of Educational Psychology, 101, 561-576. doi: 10.1037/a0014701

Fuson, K. C. (1992). Research on whole number addition and subtraction. In D. A. Grouws (Ed.), Handbook of research on mathematics teaching and learning (pp. 243-275). New York: MacMillan.

Fuson, K. C., \& Hall, J. W. (1983). The acquisition of early number word meanings. In H. Ginsburg (Ed.), The development of mathematical thinking (pp. 49-107). New York: Academic.

Fuson, K. C., Richards, J., \& Briars, D. J. (1982). The acquisition and elaboration of the number word sequence. In C. J. Brainerd (Ed.), Progress in cognitive development research, Vol. 1, Children's logical and mathematical cognition (pp. 33-92). New York: Springer-Verlag.

Gallistel, C. R., \& Gelman, R. (2000). Non-numerical cognition: From reals to integers. Trends in Cognitive Sciences, 4, 59-65. 
Gallistel, C. R., \& Gelman, R. (2005). Mathematical cognition. In K. Holyoak, \& R. Morrison (Eds.), The Cambridge handbook of thinking and reasoning (pp. 559-588). Cambridge, UK: Cambridge University Press.

Geary, D. C. (2004). Mathematics and learning disabilities. Journal of Learning Disabilities, 37, 4-15. doi: http://dx.doi.org/10.1177/00222194040370010201

Geary, D. C. (2011). Cognitive predictors of achievement growth in mathematics: A 5-year longitudinal study. Developmental Psychology, 47, 1539-1552. doi: 10.1037/a0025510

Geary, D. C., Brown, S. C, \& Samaranayake, V. A. (1991). Cognitive addition: a short longitudinal study of strategy choice and speed-of-processing differences in normal and mathematically disabled children. Developmental Psychology, 27, 787-797. doi: $10.1037 / 0012-1649.27 .5 .787$

Geary, D. C., Hoard, M. K., \& Hamson, C. O. (1999). Numerical and arithmetical cognition: patterns of functions and deficits in children at risk for a mathematical disability. Journal of Experimental Child Psychology, 74, 213-239. doi: 10.1006/jecp.1999.2515

Geary, D. C., Hoard, M. K., Nugent, L., \& Byrd-Craven, J. (2008). Development of number line representations in children with mathematical learning disability. Developmental Neuropsychology, 33, 277-299. doi: 10.1080/87565640901982361

Gelman, R., \& Gallistel, C. R. (1978). The child's understanding of number. Cambridge, MA: Harvard University Press.

Gersten, R. \& Chard, D. (1999). Number sense: Rethinking arithmetic instruction for students with mathematic difficulties. The Journal of Special Education, 33, 18-28.

Gilmore, C., Attridge, N., Clayton, S., Cragg, L., Johnson, S., Marlow, N., Simms, V., \& Inglis, M. (2013). Individual differences in inhibitory control, not non-verbal number acuity, correlate with mathematics achievement. PLoS One, 8, e67374. doi: 10.1371/journal.pone.0067374 
Gilmore, C. K., McCarthy, S. E., \& Spelke, E. S. (2007). Symbolic arithmetic knowledge without instruction. Nature, 447, 589-591. doi:10.1038/nature05850

Gilmore, C. K., McCarthy, S. E., \& Spelke, E. S. (2010). Non-symbolic arithmetic abilities and mathematics achievement in the first year of formal schooling. Cognition, 115, 394406. doi: 10.1016/j.cognition.2010.02.002

Gilmore, C. K., \& Papadatou-Pastou, M. (2009). Patterns of individual differences in conceptual understanding and arithmetical skill: A meta-analysis. Mathematical Thinking and Learning, 11(1-2), 25-40. doi:10.1080/10986060802583923

Griffin, S. (2002). The development of math competence in the preschool and early school years: Cognitive foundations and instructional strategies. In J. M. Royer (Ed.), Mathematical cognition (pp. 1-32). Greenwich, CT: Information Age Publishing.

Halberda, J., \& Feigenson, L. (2008). Developmental change in the acuity of the "Number sense": The approximate number system in 3-, 4-, 5-, and 6-year-olds and adults. Developmental Psychology, 44, 1457-1465. doi: 10.1037/a0012682

Hannula, M. M. (2005). Spontaneous focusing on numerosity in the development of early mathematical skills. Turku, Finland: Painosalama.

Hannula, M. M., \& Lehtinen, E. (2001). Spontaneous tendency to focus on numerosities in the development of cardinality. In M. Panhuizen-Van Heuvel (Ed.), Proceedings of the 25th Conference of the International Group for the Psychology of Mathematics Education (Vol. 3, pp. 113-120). Amersfoort, Netherlands: Drukkerij Wilco.

Hannula, M. M., \& Lehtinen, E. (2005). Spontaneous focusing on numerosity and mathematical skills of young children. Learning and Instruction, 15, 237-256. doi:10.1016/j.learninstruc.2005.04.005. 
Hannula, M. M., Lepola, J. \& Lehtinen, E. (2010). Spontaneous focusing on numerosity as a domain-specific predictor of arithmetical skills. Journal for Experimental Child Psychology. 107, 394-406. doi:10.1016/j.jecp.2010.06.004.

Hannula, M. M., Mattinen, A., \& Lehtinen, E. (2005). Does social interaction influence 3year-old children's tendency to focus on numerosity? A quasi-experimental study in daycare. In L. Verschaffel, E. De Corte, G. Kanselaar, \& M. Valcke (Eds.), Powerful learning environments for promoting deep conceptual and strategic learning. Studia Paedagogica (Vol. 41, pp. 63-80). Leuven, Belgium: Leuven University Press.

Hannula, M. M., Räsänen, P., \& Lehtinen, E. (2007). Development of counting skills: Role of spontaneous focusing on numerosity and subitizing-based enumeration. Mathematical Thinking and Learning, 9, 51-57. doi:10.1207/s15327833mt10901_4

Hannula-Sormunen, M. M. (in press). Spontaneous focusing on numerosity and its relation to counting and arithmetic. Oxford Handbook of Mathematical Cognition. doi: 10.1093/oxfordhb/9780199642342.013.018

Hecht, S. A., Torgesen, J. K., Wagner, R. K., \& Rashotte, C. A. (2001). The relations between phonological processing abilities and emerging individual differences in mathematical computation skills: A longitudinal study from second to fifth grades. Journal of Experimental Child Psychology, 79, 192-227. doi: 10.1006/jecp.2000.2586

Holloway, I. D., \& Ansari, D. (2009). Mapping numerical magnitudes onto symbols: The numerical distance effect and individual differences in children's mathematics achievement. Journal of Experimental Child Psychology, 103, 17-29. doi: 10.1016/j.jecp.2008.04.001

Hooper, S. R., Roberts, J., Sideris, J., Burchinal, M., \& Zeisel, S. (2010). Longitudinal predictors of reading and math trajectories through middle school from African American 
versus Caucasian students across two samples. Developmental Psychology, 46, 1018 1029. doi: $10.1037 / \mathrm{a} 0018877$

Juel, C. (1988). Learning to read and write: A longitudinal study of 54 children from first through fourth grades. Journal of Educational Psychology, 80, 437-447. doi: $10.1037 / 0022-0663.80 .4 .437$

Kadosh, R. C., \& Walsh, V. (2009). Numerical cognition: Reading numbers from the brain. Current Biology, 19, R898-R899. doi: 10.1016/j.cub.2009.08.033

Kleemans, M., Peeters, M., Segers, E., \& Verhoeven, L. (2012). Child and home predictors of early numeracy skills in kindergarten. Early Childhood Research Quarterly, 27, 471-477. doi: 10.1016/j.ecresq.2011.12.004

Koponen, T., Aunola, K., Ahonen, T., \& Nurmi, J. E. (2007). Cognitive predictors of singledigit and procedural calculation skills and their covariation with reading skill. Journal of Experimental Child Psychology, 97, 220-241. doi:10.1016/j.jecp.2007.03.001

Koponen, T., Salmi, P., Eklund, K., \& Aro, T. (2012). Counting and RAN: Predictors of arithmetic calculation and reading fluency. Journal of Educational Psychology, 105, 162175. doi: $10.1037 / \mathrm{a} 0029285$

Krajewski, K., \& Schneider, W. (2009). Early development of quantity to number-word linkage as a precursor of mathematical school achievement and mathematical difficulties: Findings from a four-year longitudinal study. Learning and Instruction, 19, 513-526. doi:10.1016/j.learninstruc.2008.10.002

Landerl, K., Bevan, A., \& Butterworth, B. (2004). Developmental dyscalculia and basic numerical capacities: A study of 8-9-year-old students. Cognition, 93, 99-125. doi: 10.1016/j.cognition.2003.11.004 
Le Corre, M., \& Carey, S. (2007). One, two, three, four, nothing more: An investigation of the conceptual sources of the verbal counting principles. Cognition, 105, 395-438. doi: 10.1016/j.cognition.2006.10.005

LeFevre, J. A., Fast, L., Skwarchuk, S., Smith-Chant, B. L., Bisanz, J., Kamawar, D., \& Penner-Wilger, M. (2010). Pathways to mathematics: Longitudinal predictors of performance. Child Development, 81, 1753-1767. doi:10.1111/j.1467-8624.2010.01508.x

LeFevre, J. A., Polyzoi, E., Skwarchuk, S., Fast, L., \& Sowinski, C. (2010). Do home numeracy and literacy practices of Greek and Canadian parents predict the numeracy skills of kindergarten children? International Journal of Early Years Education, 18(1), 55-70. doi: http://dx.doi.org/10.1080/09669761003693926

LeFevre, J. A., Skwarchuk, S., Smith-Chant, B. L., Fast, L., Kamawar, D., \& Bisanz, J. (2009). Home numeracy experiences and children's math performance in the early school years. Canadian Journal of Behavioural Science, 41(2), 55-66. doi: 10.1037/a0014532

Lipton, J. S., \& Spelke, E. S. (2005). Preschool children's mapping of number words to nonsymbolic numerosities. Child Development, 76, 978-988. doi: 10.1111/j.14678624.2005.00891.x

Lyons, I. M., Ansari, D., \& Beilock, S. L. (2012). Symbolic estrangement: Evidence against a strong association between numerical symbols and the quantities they represent. Journal of Experimental Psychology: General, 141, 635-641. doi 10.1037/a0027248

Martin, R. B., Cirino, P. T., Sharp, C., \& Barnes, M. (2014). Number and counting skills in kindergarten as predictors of grade 1 mathematical skills. Learning and Individual Differences, 34, 12-23. http://dx.doi.org/10.1016/j.lindif.2014.05.006

Matthews, J. S., Ponitz, C. C., \& Morrison, F. J. (2009). Early gender differences in selfregulation and academic achievement. Journal of Educational Psychology, 101, 689-704. doi: $10.1037 / \mathrm{a} 0014240$ 
McClelland, M. M., Cameron, C. E., Connor, C. M., Farris, C. L., Jewkes, A. M., \& Morrison, F. J. (2007). Links between behavioral regulation and preschoolers' literacy, vocabulary, and math skills. Developmental Psychology, 43, 947-959. doi: 10.1037/00121649.43.4.947

Moeller, K., Pixner, S., Kaufmann, L., \& Nuerk, H. C. (2009). Children's early mental number line: Logarithmic or decomposed linear? Journal of Experimental Child Psychology, 103, 503-515. doi: 10.1016/j.jecp.2009.02.006

Mundy, E., \& Gilmore, C. K. (2009). Children's mapping between symbolic and nonsymbolic representations of number. Journal of Experimental Child Psychology, 103, 490-502. doi: 10.1016/j.jecp.2009.02.003

Nunes, T., \& Bryant, P. (1996). Children doing mathematics. Oxford: Blackwell.

Nunes, T., Bryant, P., Barros, R., \& Sylva, K. (2012). The relative importance of two different mathematical abilities to mathematical achievement. British Journal of Educational Psychology, 82, 136-156. doi: 10.1111/j.2044-8279.2011.02033.x

Nunes, T., Bryant, P., Evans, D., Bell, D., Gardner, S., Gardner, A., \& Carraher, J. (2007). The contribution of logical reasoning to the learning of mathematics in primary school. British Journal of Developmental Psychology, 25, 147-166. doi: $10.1348 / 026151006 \times 153127$

Obersteiner, A., Reiss, K., \& Ufer, S. (2013). How training on exact or approximate mental representations of number can enhance first-grade students' basic number processing and arithmetic skills. Learning and Instruction, 23, 125-135.

doi:10.1016/j.learninstruc.2012.08.004

Petitto, A. L. (1990). Development of numberline and measurement concepts. Cognition and Instruction, 7, 55-78. doi: http://dx.doi.org/10.1207/s1532690xci0701_3

Piaget, J. (1952). The child's conception of number. London: Routledge \& Kegan Paul. 
Piaget, J., Inhelder, I., \& Szeminska, A. (1960). The child's conception of geometry. London: Routledge \& Kegan Paul.

Piaget, J., \& Szeminska, A. (1952). The child's conception of number. London: Routledge.

Piasta, S. B., Purpura, D. J., \& Wagner, R. (2010). Developing early literacy skills: The impact of alphabet instruction. Reading \& Writing, 23, 607-626. doi: 10.1598/RRQ.45.1.2

Piazza, M., Facoetti, A., Trussardi, A. N., Berteletti, I., Conte, S., Lucangeli, D., Dehaene, S., \& Zorzi, M. (2010). Developmental trajectory of number acuity reveals a severe impairment in developmental dyscalculia. Cognition, 116, 33-41. doi:

10.1016/j.cognition.2010.03.012

Potter, E. (2009). Spontaneous focusing on numerosity: Motivational and skill correlates in young children in a public preschool and kindergarten program. In S. L. Swars, D. W. Stinson, \& S. Lemons-Smith (Eds.), Proceedings of the $31^{\text {st }}$ annual meeting of the North American Chapter of the International Group for the Psychology of Mathematics Education Vol. 5 (pp. 152-155). Atlanta, GA: Georgia State University Press.

Purpura, D. J., Hume, L., Sims, D., \& Lonigan, C. J. (2011). Emergent literacy and mathematics: The value of including emergent literacy skills in the prediction of mathematics development. Journal of Experimental Child Psychology, 110, 647-658. doi: 10.1016/j.jecp.2011.07.004

Ramani, G. B., \& Siegler, R. S. (2008). Promoting broad and stable improvements in lowincome children's numerical knowledge through playing number board games. Child Development, 79, 375-394. doi: 10.1111/j.1467-8624.2007.01131.x

Ramani, G. B. \& Siegler, R. S. (2011). Reducing the gap in numerical knowledge between low- and middle-income preschoolers. Journal of Applied Developmental Psychology, 32, 146-159. doi: 10.1016/j.appdev.2011.02.005 
Räsänen, P., Salminen, J., Wilson, A. J., Aunio, P., \& Dehaene, S. (2009). Computer-assisted intervention for children with low numeracy skills. Cognitive Development, 24, 450-472. doi: 10.1016/j.cogdev.2009.09.003

Romano, E., Babchishin, L., Pagani, L. S., \& Kohen, D. (2010). School readiness and later achievement: Replication and extension using a nationwide Canadian survey. Developmental Psychology, 46, 995-1007. doi: 10.1037/a0018880

Rousselle, L., \& Noël, M. P. (2007). Basic numerical skills in children with mathematics learning disabilities: A comparison of symbolic vs non-symbolic number magnitude. Cognition, 102, 361-395. doi: 10.1016/j.cognition.2006.01.005

Sasanguie, D. (2013). The development of basic number processes and the relation with mathematics achievement (doctoral dissertation). KU Leuven, Leuven.

Sasanguie, D., Defever, E., Van den Bussche, E., \& Reynvoet, B. (2011). The reliability of and the relation between non-symbolic numerical distance effects. Acta Psychologica, 136, 73-80. doi: 10.1016/j.actpsy.2010.10.004

Savage, R., Carless, S., \& Ferraro, V. (2007). Predicting curriculum and test performance at age 11 years from pupil background, baseline skills and phonological awareness at age 5 years. Journal of Child Psychology and Psychiatry, 48, 732-739.

http://dx.doi.org/10.1111/j.1469-7610.2007.01746.x

Sénéchal, M., \& LeFevre, J. A. (2002). Parental involvement in the development of children's reading skill: A five-year longitudinal study. Child Development, 73, 445-460. doi: $10.1111 / 1467-8624.00417$

Siegler, R. S., \& Opfer, J. E. (2003). The development of numerical estimation: Evidence for multiple representations of numerical quantity. Psychological Science, 14, 237-243. doi: $10.1111 / 1467-9280.02438$ 
Siegler, R. S., \& Ramani, G. B. (2008). Playing linear numerical board games promotes lowincome children's numerical development. Developmental Science, 11, 655-661. doi: 10.1111/j.1467-7687.2008.00714.x

Siegler, R. S., \& Ramani, G. B. (2009). Playing linear number board games-but not circular ones-improves low-income preschoolers' numerical understanding. Journal of Educational Psychology, 101, 545-560. doi: 10.1037/a0014239

Simms, V., Muldoon, K., \& Towse, J. (2013). Plane thinking: Mental representations in number line estimation as a function of orientation, scale and counting proficiency. Journal of Experimental Child Psychology, 115, 468-480. doi:

10.1016/j.jecp.2013.03.011

Skwarchuk, S. L., Sowinski, C., \& LeFevre, J. A. (2014). Formal and informal home learning activities in relation to children's early numeracy and literacy skills: The development of a home numeracy model. Journal of Experimental Child Psychology, 121, 63-84. doi: 10.1016/j.jecp.2013.11.006

Storch, S. A., \& Whitehurst, G. J. (2002). Oral language and code-related precursors to reading: Evidence from a longitudinal structural model. Developmental Psychology, 38, 934-947. doi: 10.1037//0012-1649.38.6.934

Toll, S. W. M., \& Van Luit, J. E. H. (2014). The developmental relationship between language and low early numeracy skills throughout kindergarten. Exceptional Children, 81, 64-78. doi: 10.1177/0014402914532233

Torbeyns, J., De Smedt, B., Stassens, N., Ghesquière, P.,\& Verschaffel, L. (2009). Solving subtraction problems by means of indirect addition. Mathematical Thinking and Learning, 11(1-2), 79-91. doi: 10.1080/10986060802583998

Vergnaud, G. (1982). A classification of cognitive tasks and operations of thought involved in addition and subtraction problems. In T. P. Carpenter, J. M. Moser, \& T. A. Romberg 
(Eds.), Addition and subtraction: A cognitive perspective (pp. 60-67). Hillsdale, NJ: Erlbaum.

Verschaffel, L., Baroody, A. J., \& Torbeyns, J. (2009). Young children's understanding and application of subtraction-related principles. Mathematical Thinking and Learning, 11(12), 2-9. doi: http://dx.doi.org/10.1080/10986060802583873

Verschaffel, L., Greer, B., \& De Corte, E. (2007). Whole number concepts and operations. In F. K. Lester (Ed.), Second handbook of research on mathematics teaching and learning (pp. 557-628). Greenwich, CT: information Age Publishing.

Wagner, J. B., \& Johnson, S. C. (2011). An association between understanding cardinality and analog magnitude representations in preschoolers. Cognition, 119(1), 10-22. doi: 10.1016/j.cognition.2010.11.014

Wagner, R. K., \& Torgesen, J. K. (1987). The nature of phonological processing and its causal role in the acquisition of reading skills. Psychological Bulletin, 101, 192-212. doi: 10.1037/0033-2909.101.2.192

Welsh, J. A., Nix, R. L., Blair, C., Bierman, K. L., \& Nelson, K. E. (2010). The development of cognitive skills and gains in academic school readiness for children from low-income families. Journal of Educational Psychology, 102, 43-53. doi: 10.1037/a0016738

Whyte, J. C. \& Bull, R. (2008). Number games, magnitude representation, and basic number skills in preschoolers. Developmental Psychology, 44, 588-596. doi: 10.1037/00121649.44.2.588

Wilson, A. J., Dehaene, S., Dubois, O., \& Fayol, M. (2009). Effects of an adaptive game intervention on accessing number sense in low-socioeconomic-status kindergarten children. Mind, Brain, and Education, 3, 224-234.

Wynn, K. (1992). Children's acquisition of the number words and the counting system. Cognitive Psychology, 24, 220-251. doi:10.1016/0010-0285(92)90008-P 
Xenidou-Dervou, I, De Smedt, B, van der Schoot, M., \& van Lieshout, E. C. D. M. (2013). Individual differences in kindergarten math achievement: The integrative roles of approximation skills and working memory. Learning and Individual Differences, 28, 119-129. doi: 10.1016/j.lindif.2013.09.012

Xu, F., \& Spelke, E. S. (2000). Large number discrimination in 6-month-old infants.

Cognition, 74, B1-B11. doi: 10.1016/S0010-0277(99)00066-9 